\title{
AN INNOVATIVE REPURPOSING OF MEFLOQUINE; ASSESSMENT OF ITS THERAPEUTIC EFFICACY IN TREATING CRYPTOSPORIDIUM PARVUM INFECTION OF BOTH IMMUNOCOMPETENT AND IMMUNOCOMPROMIZED MICE
}

By

\author{
NAGWA SHABAN MOHAMED ALY ${ }^{1 *}$, RABAB FAWZY SELEM ${ }^{1}$, RABAB \\ SAYED ZALAT ${ }^{2}$, HEBA KHALIL ${ }^{3}$ AND BOSHRA EL-SAYED TALHA HUSSIEN ${ }^{4}$ \\ Department of Parasitology ${ }^{1}$, Faculty of Medicine, Benha University ${ }^{1}$, and \\ Departments of Parasitology ${ }^{2}$ and Pathology ${ }^{3}$, Theodore Bilharz Research Institute, \\ Imbaba P. O. Box 30, Giza, and Department of Tropical Medicine ${ }^{4}$, Faculty of \\ Medicine, Tanta University, Egypt ( ${ }^{*}$ Correspondence: nagwa.ali@fmed.bu.edu.eg)

\section{Abstract}

Cryptosporidium parvum is a protozoan parasite can affect humans, worldwide, causing asymptomatic infections or diarrheal disease, which may be life-threatening in immunocompromised and neonatal individuals. Mefloquine is one of the most promising anti-parasitic drugs. The present report aimed to study the in-vivo efficacy of Mefloquine when applied inimmunocompetent and immunocompromised cryptosporidiosis-infected mice groups, each of the them was subclassified into the following groups :non-infected non-treated group (normal control), infected non-treated group (infected control), nitazoxanide treated group and Mefloquine treated group. One week post infection, treated groups received either Nitazoxanide (100mglKg daily for 5 days) or single dose of Mefloquine $(400 \mathrm{mg} / \mathrm{Kg}$ ). Two weeks post treatment, all mice were scarified. Stool samples and intestinal histopathological specimens were examined. For both drugs, immunocompetent groups showed better parasitological clearance than immunocomporomized one. Cryptosporidium oocyst reduction rates with Nitazoxanide (NTZ) and Mefloquine were 53.3\%, and 61.6\% respectively in the immunocompetent groups. The corresponding rates in immunocompromised groups were $49.93 \%$ and $60.03 \%$.for NTZ and Mefloquine respectively. A single dose of Mefloquine treatment $(400 \mathrm{mg} / \mathrm{kg})$ resulted in higher oocyst reduction rates than the approved anti-cryptosporidiosis drug (Nitazoxanide with five days application regimen).The histopathological study supported the parasitological findings as mefloquine treated mice tissue showed mild to moderate inflammatory changes while that of other groups ranged from moderate to severe alterations in the mice tissue. These results showed that Mefloquine which is FDA approved, already marketed and commercially available on a global scale has an excellent anti parasitic activity against $C$. parvum infection with single dose application; which saves time, cost and efforts to search for additional or alternative drugs for treating cryptosporidiosis. More large scale studies are needed to illustrate its dose response relationship using multiple doses regimens, performance and limitations on immunocompromized population, synergistic effect with already approved drugs, mechanism of action on Cryptosporidium parasite and its possible role in chemoprophylaxis specially for high risk individuals.

Key words: Cryptosporidium parvum, Mefloquine, Nitazoxanide, In-Vivo,

\section{Introduction}

Cryptosporidium parvum is an internationally distributed protozoan parasite that is existed in both vertebrates and invertebrates (Lima et al, 2011).Infections are transmitted by fecal-oral route, or through contaminated food or water, and many major waterborne outbreaks have occurred (Yoder and Beach, 2010). Cryptosporidiosis represents a foremost health problem as it was a frequent cause of diarrhea in both immunocompetent and immunodeficient individuals (Rossignol, 2010), all over the world (Yoder et al, 2012; Insulander et al, 2013). Nitazoxanide is the only approved drug for treatment of diarrhea caused by Cryptosporidium infection (Mainali et al, 2013). But, it showed imperfect efficacy in the most vulnerable patients (Amadi et al, 2002; Abubakar et al, 2007; Manjunatha et al, 2016). Besides, the dependence of a one drug as sole effective treatment for any microorganism is known 
to carry an inevitable risk of electing resistant strains and failure of treatment. Hence, development of new effective drug for cryptosporidiosis represents a pressing need. Drug repurposing (also termed re-profiling, re-tasking, therapeutic switching or drug repositioning) is the process of developing new indications for existing, failed or abandoned drugs or advanced clinical candidates (Sekhon, 2013). Drug repurposing was a useful strategy to accelerate drug development process due to lower costs, little risk and decreased time to market due to availability of preclinical data (Padhy and Gupta, 2011). This enables not only pharmaceutical companies but also public-sector researchers to engage in drug discovery and development efforts (O'Connor and Roth, 2005), and hence might result in treatment options for diseases almost exclusively addressed by public sector researchers, such as the neglected tropical diseases. Mefloquine is a 4quinolinemethanol synthetic antimalarial analogue of quinine developed in 1971 (Kumar et al, 2009). Years later, it proved to be more than antimalarial drug and gave excellent antiparasitic activities including antischistosomal one (Keiser et al, 2010; Ingram et al, 2012; Basra et al, 2013; Xiao et al, 2013; Abou-Shady et al, 2016). Besides, antischistosomial activity, Keiser et al. (2010) reviewed the effectiveness of mefloquine against food-borne trematodes and highlighted that mefloquine was not active against Fasciola hepatica or Clonorchis sinensis, but was active against juvenile and adult $O p$ isthorchis viverini in a hamster infection (Keiser et al, 2009a). But, mefloquine failed to be effective against $O$. viverini in clinical trials (Soukhathammavong et al, 2011). Also, mefloquine yielded significant results against $C$. sinensis infection in a rat model and Paragonimus westermani in a dog model, but was not better than praziquantel (Xiao et al, 2010). Mefloquine proved activity against Babesia in man and dogs (El-Bahnasawy et al, 2011; Munkhjargal et al, 2012), Echinococcus multilocularis (Küster et al,
2015) and adult Fasciola gigantica (Shalaby et al, 2016).

The aim of this study was to explore the efficacy of mefloquine against cryptosporidiosis infection in a controlled study including both the immuno-competent and the immuno-compromized mice.

\section{Materials and Methods}

This study was carried out on laboratory bred Swiss albino female mice $(n=80)$ weighing about $20 \mathrm{gm}$. They were categorized into the following eight groups of ten mice each: GI: Immunocompetent, infected non treated mice, GII: Immunocompetent, infected animals treated with nitazoxanide orally $100 \mathrm{mg} / \mathrm{kg}$ ( $\mathrm{Li}$ et al, 2003) daily for five consequent days, one week post infection, GIII: Immunocompetent-infected mice treated with mefloquine orally $400 \mathrm{mg} / \mathrm{Kg}$ single dose (Keiser et al, 2009b), a week post infection. GIV: Immunocompetent, non-infected non treated, GV: Immunocompromized, infected non treated mice, GVI: Immunocompromised, infected animals treated with nitazoxanide orally (0.04-mg/mouse/day) daily for five consequent days, a week post infection, GVII: Immunocompromised, infected mice treated with mefloquine orally $400 \mathrm{mg} / \mathrm{Kg}$ single dose, a week post infection and GVIII: Immunocompromised, non-infected non-treated. The animals were sacrificed two weeks post treatment.

Immunosuppression was performed by giving the animals synthetic corticosteroids (dexamethasone) orally at a dose of $0.25 \mathrm{mg}$ /g/day for 14 successive days prior to inoculation with Cryptosporidium oocysts (Rehg et al, 1988). Cryptosporidium oocysts were obtained from naturally infected calves (slaughter houses) by collection of scrapings of the ileal mucous membrane and fecal content (Anderson, 1985). The samples were examined for confirmation of the presence of oocysts by modified Ziehl-Neelsen staining method (Henriksen and Pohlen, 1981). The infective samples were preserved by mixing with an equal volume of $2.5 \%$ Potassium dichromate (K2Cr2O7), after Campbell and 
Current (1983). Infective inoculum was prepared (Reese et al, 1982) and the number of oocysts in the concentrated stock inoculum was counted to determine how much the fluid volume was the inoculum per mouse.

All mice in the studied groups except the control groups were infected orally with the prepared inoculum of Cryptosporidium oocysts; this occurred on day 15 of dexamethasone in immunosuppressed groups (Moon et $a l, 1982)$. The animals were deprived of water overnight, and were then inoculated intraesophageally with the prepared inoculums using a tuberculin syringe connected to a polythene tube. The amount given to each mouse was adjusted to contain approximately 1000 oocysts/mouse (Gaafar, 2007). Two weeks post treatment, all mice were scarified. Stool samples and intestinal histopathology were examined. Mefloquine hydrochloride (Lariam 250mg tablets) was obtained from ROCH Co. Nitazoxanide (Nanazoxid100mg) was provided by Medizen Pharmaceutical Industries for Utopia Pharmaceuticals.

Assessment of infection and the drug effect: 1- Stool examination: Fresh fecal pellets from each mouse in the study groups were collected separately. Each sample was suspended in $10 \%$ formalin and homogenized. Then, $1 \mathrm{mg}$ was prepared as a fecal smear and stained by the modified ZiehlNeelsen staining method. The stained fecal smear was examined microscopically and number of oocysts was counted in 10 highpower fields (Mohamed et al, 2015).

2- Histopathological examination: The terminal $2 \mathrm{~cm}$ of the ileum was submitted to routine histopathological processing at the Department of Pathology, TBRI, where they were fixed in $10 \%$ neutral buffered formalin, dehydrated in ascending grades of ethanol, followed by immersion in xylene, and then impregnated in paraffin. Two 5-mm thick sections were taken from each block. One section was stained with hematoxylin and eosin for evaluation, and then examined by light microscopy for assessing the histopathological changes (Tzipori et al, 1981).

Statistical analysis: Data were collected, tabulated, and statistically analyzed using SPSS program version 11. ANOVA test was used for detection of variation between the groups. Post hoc Bonferoni test was used for pair wise comparisons between groups. Unpaired Student $t$ test was used to assess if the host immune status influenced performance of drugs by comparing mean oocyst count of immunocompetent and immunocompromized groups. The percentage infection reduction rate was assessed using the formula: (mean value of infected untreated groupmean value of infected- treated group) x100/mean va-lue of infected- untreated group (Abdel Sal-am et al, 2008).

A $p$-value equal to or less than 0.05 was considered significant and less than 0.01 was considered highly significant.

\section{Results}

Table 1: Comparison between means of oocyst number in infected non-treated control, NTZ \& Mefloquine treated immunocompetent mice groups.

\begin{tabular}{|l|l|c|c|c|c|}
\hline Oocyst count & infected control $(\mathrm{N}=10)$ & NTZ $(\mathrm{N}=10)$ & Mefloquine $(\mathrm{N}=9)$ & $P$ value & $F$ \\
\cline { 1 - 4 } Mean $+\mathrm{SD}$ & $33517.1+5320.1$ & $15636.3+6300.4$ & $12856.8+3061.7$ & \multirow{2}{*}{$<0.001$} & 46,385 \\
\hline Range & $24750-43333$ & $1366.3-27000$ & $8222.2-19200$ & & \\
\hline
\end{tabular}

There was a highly significant difference between infected control mean oocysts count and that of NTZ and mefloquine treated immunocompetent mice, but mefloquine gave an observably lower mean oocyst count that reflected on mean oocysts count reduction rate of both groups; $53.3 \%$ for NTZ group and $61.6 \%$ for mefloquine treated one.
Pairwise comparison between groups using Bonferroni post hoc test showed tno significant difference between mean Cryptosporidium oocysts count of NTZ and mefloquine treated immunocompetent mice $P$ value $=0.750$, denoting that the mefloquine efficacy was comparable to the NTZ with the upper hand for the former drug. 
Table 2: Comparison between means of oocyst number in infected non treated control, NTZ and Mefloquine treated immunocompormized mice.

\begin{tabular}{|l|c|c|c|c|c|}
\hline Oocyst count & Infected control $(\mathrm{N}=10)$ & $\mathrm{NTZ}(\mathrm{N}=10)$ & Mefloquine $(\mathrm{N}=10)$ & $P$ value & $F$ \\
\hline Mean \pm SD & $46973.95 \pm 11018$ & $23511.99 \pm 8117.1$ & $18767.6 \pm 5742.3$ & $<0.001$ & 31.067 \\
\cline { 1 - 6 } Range & $34888.9-72000$ & $13555.6-39000$ & $10888.9-25600$ & & \\
\hline
\end{tabular}

There was a highly significant statistical difference between infected control group mean Cryptosporidium oocysts count and that of NTZ and mefloquine treated immunocomporomized mice groups, though mefloquine ones showed an observably lower mean oocysts count which was reflected on the mean oocyst count reduction rate of both groups $; 49.9 \%$ for NTZ group and $60 \%$ for

Table 3: Comparison between NTZ and mefloqu

\begin{tabular}{|c|c|c|c|c|}
\hline Immune status & Immuno competent & Immunocompromized & $t$ & $P$ value \\
\hline NTZ & $15636.3 \pm 6300.4$ & $23511.99 \pm 8117.1$ & 2.4238 & 0.0261 \\
\hline Mefloquine & $12856.8 \pm 3061.7$ & $18767.6 \pm 5742.3$ & 2.7510 & 0.0136 \\
\hline
\end{tabular}

In NTZ and mefloquine treated mice, oocyst mean counts were substantially impacted by host immune status as they were significantly higher in the immunocompromized groups treated by both drugs.

The histopathological examination in this study was performed just to roughly assess our hypothesis regarding the mefloquine anticryptosporial activity as manifested by the degree of inflammatory changes in small intestine tissue and not to measure its effect the on the intensity of infection. As seen in figures $(1,2,3 \& 4)$, the histopathological screening study results supported that of parasitological ones. The infected non treated samples showed sever villous atrophy and inflammatory cells infiltrations .There was a mild to moderate inflammatory reaction in the mefloquine treated mice samples while the intensity of inflammation ranged from moderate to marked in the corresponding NTZ samples as compared with the control samples.

\section{Discussion}

Cryptosporidiosis may become life threatening which can lead to death in some individuals specifically children and immnosuppressed patients. There was no completely satisfactory treatment for the cryptosporidial enteritis successfully developed (Castella- mefloquine treated one .Pairwise comparison between various groups using Bonferro$n i$ post hoc test showed that there was no statistically significant difference between the mean Cryptosporidium oocysts count of NTZ and mefloquine treated immunocompetent mice $P$ value $=0.679$, denoting that mefloquine efficacy was comparable to that of NTZ with the upper hand for the earlier.

nos-Gonzalez et al, 2016). Consequently, probing for an alternate effective therapy is a worthy research area. Mefloquine therapeutic efficacy has been proved for many other parasites (Xiao et al, 2010; Munkhjargal et al, 2012; Basra et al, 2013; Xiao et al, 2013; Küster et al, 2015; Shalaby et al, 2016; Abou-Shady et al, 2016), but up till now to our knowledge ,there are no studies in the literature about repurposing it for treatment of Cryptosporidium parvum parasite infection.In this study, both NTZ and mefloquine treatment resulted in a partial parasitological clearance of subjected mice as manifested by the highly significant statistical difference between the mean $C$. parvum oocyst count in the treated groups as compared by the infected non treated one. These findings were valid for both immunocompetent and immunocompromized mice groups. In both NTZ and mefloquine treated mice the mean Cryptosporidium oocyst count was significantly higher in immunocompromized. Theoretically, this could be due to the logic profound replication of Cryptosporidium parasites happens as a result of dexamethazone induced immunosuppression so as to this enormous number exceeds the top limit of antiparasitic capabilities of both drugs and eventually mounting the parasite yield upon 
treatment. On the molecular level, the dexamethazone inhibitory effect on CD4 cells numbers (Parimi et al, 1999) was substantially contributing to this finding as the ultimate control of Cryptosporidium parasite infection in adult mice is dependent on CD4 T cells (Aguirre et al, 1994; Schmidt et al, 2001). Consequently, in face of this dexamethazone induced CD4 declining numbers, it seems that even potent antiprotozoal agents as NTZ and mefloquine cannot affect the parasite replicating and infecting activities as if the immune system is working properly. This agreed with Amadi et al. (2009) reported the attenuating effect of the immunosuppressed status caused by HIV infection in children on NTZ therapeutic efficacy, even after applying a high dose prolonged treatment regimen. Also, Amadi et al. (2002); Abubakar et al. (2007) and Manjunatha et al. (2016) demonstrated the NTZ inadequacy in presence of immunocompromization status. The therapeutic effect of NTZ on Cryptosporidium infection in mice was previously reported since long time by others (Theodos et al, 1998; Blagburn et al, 1998; Gargala et al, 2000). Interestingly, mefloquine treated mice showed a higher Cryptosporidium oocyst reduction rates than the NTZ in both immumocompetetant and immunocompromized mice, though the difference was statistically insignificant, but in view of the difference in dosage regimen between mefloquine (single dose) and NTZ (five consequent doses), we can effortlessly expect much better performance for mefloquine if used in a repeated dosage system.

Generally, the histopathological study results supported the parasitological data, in mefloquine treated groups it showed mild to moderate degree of intestinal tissue inflammation, while that of NTZ ranged from themoderate to marked inflammatory changes. Being both protozoa, both belong to Apicomplexa Phylum; Sporozoa Class and Coccidia subclass, it could be hypothesized that the mechanism of mefloquine action on Cryptosporidium parasite might be related to that exerted by it on Plasmodium parasites. Plasmodium spp. could synthesize several species of sphingolipids (cell membrane component) and retrieve others from their host cells (Coppens, 2013). A pioneering study of the lipid content in P. falciparuminfected red blood cells reported a significant increase in the sphingomyelin content compared with uninfected red blood cells, probably owing to the parasite's activities (Lawrence and Cenedella, 1969). Sphingomyelins are used by the parasite to form and stabilize a tubulovesicular network (TVN) of membranes that extends from the membrane of the parasitophorous vacuole to the erythrocytic plasma membrane (Haldar, 1996; Lauer et al, 1997). Studies on the mefloquine mode of action reported that it activities through sphingomyelinase enzyme led to the excess in the ceramide production (Olliaro and Wells, 2009) and decreased infectivity in-vitro and in humans (Lauer et al, 2000; Grellepois et al, 2005; Pankova-Kholmyansky and Flescher, 2006). The excess ceramide was detrimental to the parasite (PankovaKholmyansky et al, 2003). Sphingolipid-enriched membrane micro-domains (SEMs) were glycosylphosphatidylinositol (GPI)-anchored proteins found in cell membrane and involved in various membrane functions. A primary function of SEMs was thought to regulate the protein interactions by their ability to selectively recruit or exclude proteins as well as their ability to cluster into larger platforms (Manes et al, 2003). Interestingly, in another study on Cryptosporidium parasite, SEMs were found to have a role in facilitating parasite attachment to host cellular membrane and hence affecting their infectivity. They used an in vitro model of human biliary cryptosporidiosis, demonstrated that C. parvum infection triggers the clustering of SEM components at infection sites. Thus, disruption of SEM components or inhibition of SEM platform formation decreases Cryptosporidium attachment to and entry of cultured cholangiocytes. Also, the authors reported that clustering of SEM components at 
infection sites appeared to be involved in the aggregation of Gal/GalNAc-associated membrane receptors and Cryptosporidium-induced activation of the PI-3K/Cdc42/actin signalling pathway, processes were associated with parasite attachment to host cells and subsequent cellular entry. Thus, SEMs are required for $C$. parvum attachment to and entry of the host cells, likely via clustering of membrane-binding proteins and facilitating of $C$. parvum-induced actin remodelling at infection sites via activation of the PI$3 \mathrm{~K} / \mathrm{Cdc} 42$ signalling pathway (Nelson et al, 2006). Since mefloquine proved to be a potent sphingomyelinase enzyme activator $(\mathrm{Pa}-$ nkova-Kholmyansky et al, 2003), theoretically it could affect SEMs in which sphingomyelin is a basic constituent (Manes et al, 2003) and consequently, hinder the ability of Cryptosporidium parasite to attach, infect and form the tubulovesicular network necessary for its biology.

\section{Conclusion}

Mefloquine is an effective, well characterized and FDA approved alternative treatment for C. parvum infection. It showed a higher activity than the NTZ which is the only FDA approved for treatment of $C$. parvum infection. More large scale studies are needed to illustrate its dose response relationship using multiple doses regimens, performance and limitations on immunocompromized population, synergistic effect with already approved drugs, mechanism of action on Cryptosporidium parasite and its possible role in chemoprophylaxis specially for high risk individuals. Clinical trials could be instantly and effortlessly designed, approved and executed as it is already marketed drug.

\section{References}

Abdel Salam, AM, Ammar, N, Abdel Hamid, AZ, 2008: Evaluation of probiotic labenah supplemented with garlic or onion oil against Schistosoma mansoni in infected mice. Int. J. dairy Sci. 3:97-104.

Abou-Shady, OM, Mohammed, SS, Attia, SS, Yusuf, HA, Helmy, DO, 2016: Therapeutic effect of mefloquine on Schistosoma mansoni in experimental infection in mice. J. Parasitol. Dis.
Dis. 40, 2:259-67.

Abubakar, I, Aliyu, SH, Arumugam, C, Hunter, PR, Usman, NK, 2007: Prevention and treatment of cryptosporidiosis in immunocompromised patients. Cochrane Database Syst Rev. 1:CD004932.

Aguirre, SA, Mason, PH, Perryman, LE, 1994: Susceptibility of major histocompatibility complex (MHC) class I- and MHC class IIdeficient mice to Cryptosporidium parvum infection. Infect. Immun. 62:697-9.

Amadi, B, Mwiya, M, Musuku, J, Watuka, A, Sianongo, S, et al, 2002: Effect of nitazoxanide on morbidity and mortality in Zambian children with cryptosporidiosis: a randomised controlled trial. Lancet 360:1375-80.

Amadi, B, Mwiya, M, Sianongo, S, Payn, L, Watuka, A, et al, 2009: High dose prolonged treatment with nitazoxanide is not effective for cryptosporidiosis in HIV positive Zambian children: a randomised controlled trial. BMC Infect. Dis. 9, 195. http://doi.org/10.1186/1471-2334-9195.

Anderson, BC, 1985: Moist heat inactivation of Cryptosporidium sp. Am. J. Publ. Hlth.75:14334.

Basra, A, Mombo-Ngoma, G, Melser, MC, Diop, DA, Wurbel, H, et al, 2013: Efficacy of mefloquine intermittent preventive treatment in pregnancy against Schistosoma haematobium infection in Gabon: a nested randomized controlled assessor-blinded clinical trial. Clin. Infect. Dis. 56:e68-75.

Blagburn, BL, Drain, KL, Land, TM, Kinard, RG, Moore, PH, et al, 1998: Comparative efficacy evaluation of dicationic carbazole compounds, nitazoxanide, and paromomycin against Cryptosporidium parvum infections in a neonatal mouse model. Antimicrob. Agents Chemother. 42, 11:2877-82.

Campbell, PN, Current, WL, 1983: Demonstration of serum antibodies to Cryptosporidium sp. in normal and immunodeficient humans with confirmed infections. J. Clin. Microbiol.18:165-9.

Castellanos-Gonzalez, A, Sparks, H, Nava, S, Huang, W, Zhang, Z et al, 2016: A novel calcium-dependent kinase inhibitor, bumped kinase inhibitor 1517, cures cryptosporidiosis in immune-suppressed mice. J. Infect. Dis. 214, 12:18505.

Coppens, I, 2013: Targeting lipid biosynthesis and salvage in apicomplexan parasites for im- 
proved chemotherapies. Nat. Rev. Microbiol. 12:823-35.

El-Bahnasawy, MM, Khalil, HHM, Morsy, T

A, 2011: Babesiosis in an Egyptian boy acquired from pet dog, and a general review. J. Egypt. Soc. Parasitol. 41, 1:99-108.

Eraky, MA, El-Fakahany, AF, El-Sayed, NM, Abou-Ouf, EA, Yaseen, DI, 2016: Effects of Thymus vulgaris ethanolic extract on chronic toxoplasmosis in a mouse model. Parasitol. Res. 115:2863-71.

Gaafar, MR, 2007: Effect of solar disinfection on viability of intestinal protozoa in drinking water. J. Egypt. Soc. Parasitol. 37, 1:65-86.

Haldar, K, 1996: Sphingolipid synthesis and membrane formation by Plasmodium. Trends Cell Biol. 6:398-405.

Henriksen, SA, Pohlenz, JF, 1981: Staining of Cryptosporidia by a modified Ziehl-Neelsen technique. Acta Vet. Scand. 22:594-6.

Gargala, G, Delaunay, A, Li X, Brasseur, P, Favennec. L, Ballet, JJ, 2000: Efficacy of nitazoxanide, tizoxanide and tizoxanide glucuronide against Cryptosporidium parvum development in sporozoite-infected HCT-8 enterocytic cells. J. Antimicrob. Chemother. 46, 1:57-60.

Grellepois, F, Grellier, P, Bonnet-Delpon, D, Bégué, JP, 2005: Design, synthesis and antimalarial activity of trifluoromethylartemisinin-mefloquine dual molecules. Chembiochem. 6:64852.

Ingram, K, Ellis, W, Keiser, J, 2012: Antischistosomal activities of mefloquine-related arylmethanols. Antimicrob. Agents Chemother. 56, 6:3207-15.

Keiser, J, Chollet, J, Xiao, SH, Mei, JY, Jiao, PY, et al, 2009a: Mefloquine an aminoalcohol with promising antischistosomal properties in $\mathrm{mi}$ ce. PLoS. Negl. Trop. Dis. 3, 1:e350-8.

Keiser J, Odermatt P, Tesana S, 2009b: Doseresponse relationships and tegumental surface alterations in Opisthorchis viverrini following treatment with mefloquine in vivo and in vitro. Parasitol. Res. 105:261-6.

Keiser, J, Duthaler, U, Utzinger, J, 2010: Update on the diagnosis and treatment of foodborne trematode infections. Curr. Opin. Infect. Dis. 23:513-20.

Keiser, J, N'Guessan, NA, Adoubryn, KD, Silué, KD, Vounatsou, P, et al, 2010: Efficacy and safty of mefloquine, artesunate, mefloquineartesunate, and praziquantel against Schistosoma haematobium: randomized, exploratory openlabel trial. Clin. Infect. Dis. 50, 9:1205-13.

Kumar N, Singh R, Rawat D, 2009: Tetraoxanes: Synthetic and medicinal chemistry perspective. Med. Res. Rev.10.1002/med.20189

Küster, T, Stadelmann, B, Rufener, R, Risch, C, Müller, J, et al, 2015: Oral treatments of Echinococcus multilocularis-infected mice with the antimalarial drug mefloquine that potentially interacts with parasite ferritin and cystatin. Int. J. Antimicrob. Agents 46, 5:546-51.

Lauer, S A, Rathod, P K, Ghori, N and Haldar, K, 1997: A membrane network for nutrient import in red cells infected with the malaria parasite. Science 276:1122-5.

Lauer, S, VanWye, J, Harrison, T, McManus, H, Samuel, BU, et al, 2000: Vacuolar uptake of host components,anda role for cholesterol and sphingomyelin in malarial infection. EMBO J. 19, 14: 3556-64.

Lawrence, CW, Cenedella, RJ, 1969: Lipid content of Plasmodium berghei-infected rat red blood cells. Exp. Parasitol. 26:181-6.

Li, X, Brasseur, P, Agnamey, P, Leméteil, D, Favennec, L, et al, 2003: Long-lasting anticryptosporidial activity of nitazoxanide in an immunosuppressed rat model. Folia Parasitol. 50, 1:1922.

Lima, AA, Samie, A, Guerrant, RL, 2011: Cryptosporidiosis. In: Guerrant RL, Walker DH, Weller PF. Tropical infectious diseases. Philadelphia, PA: Elsevier-Churchill Livingstone.

Manes S, del Real, G, Martinez, AC, 2003: Pathogens: raft hijackers. Nat. Rev. Immunol. 3: 557-68.

Mainali, NR, Quinlan, P, Ukaigwe, A, Amirishetty, S, 2013: Cryptosporidial diarrhea in an immune-competent adult: role of nitazoxanide. J. Commu. Hosp. Int. Med. Perspect. 3, 3/4:109.

Manjunatha, UH, Chao, AT, Leong, FJ, Diagana, TT, 2016: Cryptosporidiosis drug discovery: Opportunities and challenges. ACS Infect, Dis. 2, 8:530-7.

Mohamed, EA, Zalat, RS, Magdi, M, Guirguis, N, Mahmoud S, 2015: Effect of combined therapy with Albendazole and Sutrim in experimental cryptosporidiosis. Glob. Vet. 15, 2:144-9. Moon, HW, Schwartz, A, Welch, MJ, Mc-Cann, PP, Runnels, PL 1982: Experimental fecal transmission of human Cryptosporidia to pigs, and attempted treatment with an ornithine decarboxylase inhibitor. Vet. Pathol. 19:700-7. 
Munkhjargal, T, AbouLaila, M, Terkawi, M A, Sivakumar, T, Ichikawa, M, et al, 2012: Inhibitory effects of pepstatin A and mefloquine on the growth of Babesia parasites. Am. J. Trop. Med. Hyg. 87, 4:681-8.

Nelson, JB, O'Hara, SP, Small, AJ, Tietz, PS, Choudhury, AK, et al, 2006: Cryptosporidium parvum infects human cholangiocytes via sphingolipid-enriched membrane microdomains. Cell Microbiol. 12:1932-45.

O'Connor, KA, Roth, BL, 2005: Finding new tricks for old drugs: an efficient route for publicsector drug discovery. Nat. Rev. Drug Dis. 4: 1005-14.

Olliaro, P, Wells, TN, 2009: The global portfolio of new antimalarial medicines under development. Clin. Pharmacol. Ther. 85:584-95.

Padhy, BM, Gupta, YK, 2011: Drug repositioning: re-investigating existing drugs for new therapeutic indications. J. Postgrad. Med. 57: 153-60.

Pankova-Kholmyansky, I, Flescher, E, 2006: Potential new antimalarial chemotherapeutics based on sphingolipid metabolism. Chemotherapy 52:205-9.

Pankova-Kholmyansky, I, Dagan, A, Gold, D, Zaslavsky, Z, Skutelsky E, et al, 2003: Ceramide mediates growth inhibition of the Plasmodium falciparum parasite. Cell Mol. Life Sci. 60, 3:577-87.

Parimi, PS, Birnkrant, DJ, Rao, LV, Diaz, G, Moore, JJ,1999: Effect of dexamethasone on lymphocyte subpopulations in premature infants with bronchopulmonary dysplasia. J. Perinatol. 19, 5:347-51.

Reese, NC, Current, WL, Ernst, JV, Bailey, WS, 1982: Cryptosporidiosis of man and calf: a case report and results of experimental infections in mice and rats. Am. J. Trop. Med. Hyg. 31: 226-9.

Regh, JE, Hancock, ML, Woodmansee, DB, 1988: Characterization of a dexamethasonetreated rat model of cryptosporidial infection. J. Infect. Dis. 158:1406-7.

Rossignol, JF, 2009: Cryptosporidium and Giardia: treatment options and prospects for new drugs. Exp. Parasitol. 124, 1:45-53.
Schmidt, W, Wahnschaffe, U, Schäfer, M, Zippel, T, Arvand. M, et al, 2001: Rapid increase of mucosal CD4 $\mathrm{T}$ cells followed by clearance of intestinal cryptosporidiosis in an AIDS patient receiving highly active antiretroviral therapy.

Gastroenterology 120, 4:984-7.

Sekhon, BS, 2013: Repositioning drugs and biologics: Retargeting old/existing drugs for potential new therapeutic applications. J. Pharm. Educ. Res. 4:1-15.

Shalaby, HA, El Namaky, AH Kamel, RO, 2016: In vitro tegumental alterations on adult Fasciola gigantica caused by mefloquine. J. Parasit. Dis. 40, 1:145-51.

Soukhathammavong, P, Odermatt, P, Sayasone, S, Vonghachack, Y, Vounatsou, P, et al, 2011: Efficacy and safety of mefloquine, artesunate, mefloquine-artesunate, tribendimidine, and praziquantel in patients with Opisthorchis viverrini: A randomized, exploratory, open-label, phase 2 trial. Lancet Infect. Dis. 11:110-8.

Theodos, CM, Griffiths, JK, D'Onfro, J, Fairfield, A, Tzipori, S,1988: Efficacy of nitazoxmide against Cryptosporidium parvum in cell culture and in animal models. Antimicrob. Agents Chemother. 42, 8:1959-65.

Tzipori, S, McCartney, E, Lawson, GHK, Rowland, AC, Campbell, I, 1981: Experimental infection of piglets with Cryptosporidium. Res. Vet. Sci. 31:358-68.

Xiao, SH, Utzinger, J, Tanner, M, Keiser, J, Xue, J, 2013: Advances with the Chinese anthelminthic drug tribendimidine in clinical trials and laboratory investigations. Acta Trop. 126: $115-26$.

Xiao, SH, Xue, J, Li-li, X, Zhang, YN, Qiang, HQ, 2010: Effectiveness of mefloquine against Clonorchis sinensis in rats and Paragonimus westermani in dogs. Parasitol. Res. 107:1391-7.

Yoder, JS, Beach, MJ, 2010: Cryptosporidium surveillance and risk factors in the United States. Exp Parasitol. 124:31-9.

Yoder, JS, Wallace, RM, Collier, SA, Beach, MJ, Hlavsa, MC, et al, 2012: Cryptosporidiosis surveillance United States, 2009e2010. MMWR Surveill. Summ. 61:1-12.

\section{Explanation of figures}

Fig.1: Cryptosporidium parvum oocysts count in immunocompetent groups for each individual mouse.

Fig. 2: Cryptosporidium parvum oocysts count in immunocompromized groups as recorded for each individual mouse.

Fig.3: Mean oocyst reduction rate of NTZ and mefloquine immunocompetent and immunocompromized mice.

Fig. 4: Histopathological changes of small intestine of studied groups A\& B: Non infected control mice tissue showing normal villi structure and length, no inflammatory reaction. C \&D: Infected non treated mice tissue showing acute inflammatory cells infiltrations with sever villous atrophy E,F\&G: Mefloquine treated mice tissue showing mild to moderate acute inflam- 
matory cells infiltrations with villous widening H\& I : NTZ treated mice tissue showing moderate to marked acute inflammatory cells infiltrations with villous widening
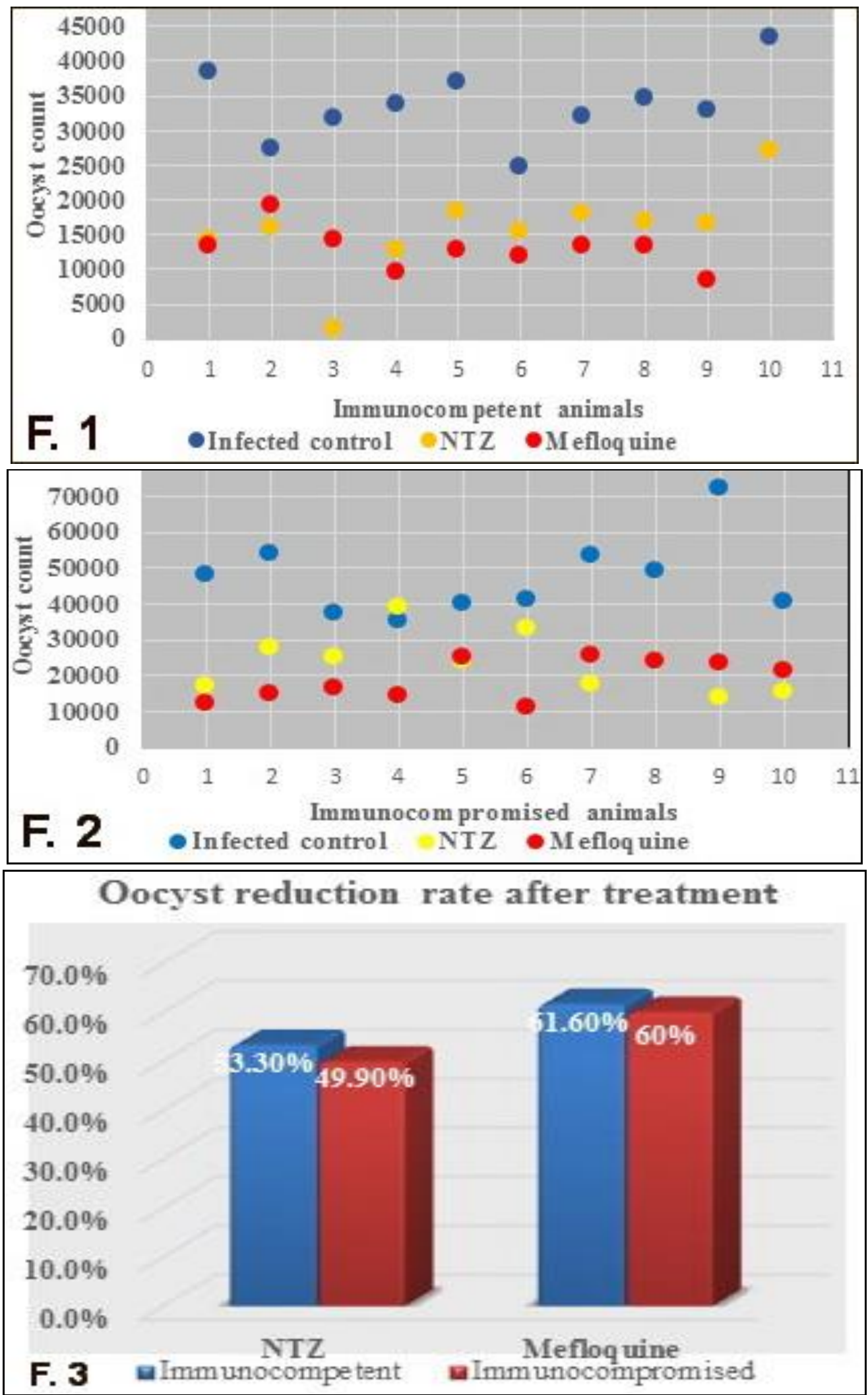


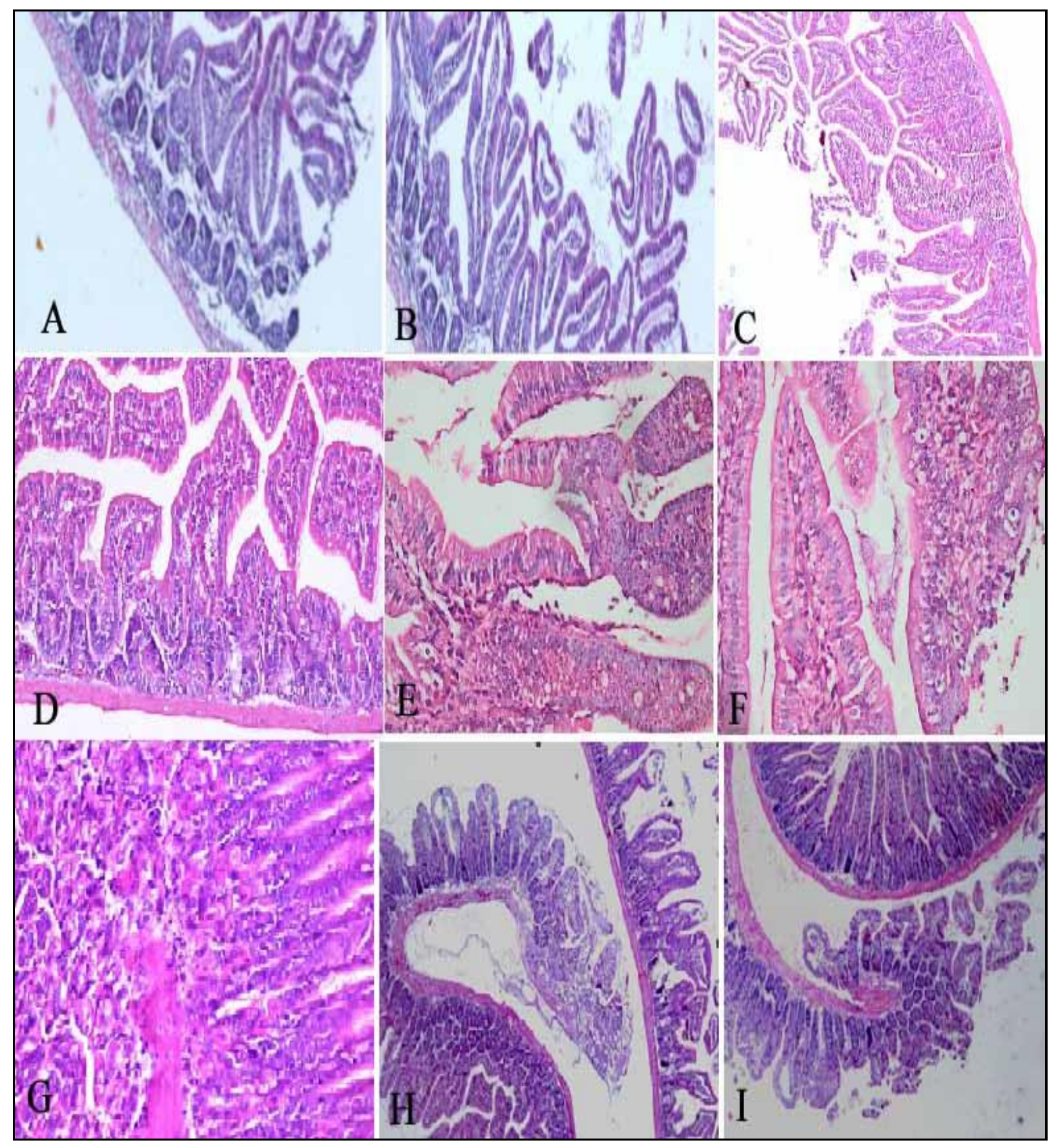

